\title{
The Distribution of Acetylcholine Receptors in Chick Ciliary Ganglion Neurons Following Disruption of Ganglionic Connections
}

\author{
Michele H. Jacob and Darwin K. Berg \\ Department of Biology, University of California, San Diego, La Jolla, California 92093
}

Chick ciliary ganglion neurons have nicotinic acetylcholine receptors (AChRs) that mediate primary chemical synaptic transmission through the ganglion. Previous studies have shown that preganglionic denervation reduces the total number of AChRs in the ganglion about 3-fold in $10 \mathrm{~d}$, while postganglionic axotomy reduces $A C h R$ levels about 10 -fold in $5 \mathrm{~d}$. Since the neurons contain large numbers of intracellular AChRs in addition to the surface AChRs, the present studies were undertaken to determine whether either surface or internal AChR pools are changed selectively by the operations.

An anti-AChR monoclonal antibody followed by an HRPconjugated secondary antibody was used to visualize $A C h R$ distributions on neurons in ciliary ganglia $5 \mathrm{~d}$ after postganglionic axotomy and $10 \mathrm{~d}$ after preganglionic denervation. Ganglia were permeabilized by treatment with saponin to obtain access to intracellular receptors. The results show that the operations do not qualitatively change the subcelIular localization of AChRs, but they do alter the levels relative to control ganglia. Axotomy produces substantial declines both in the number of synaptic AChRs and in the number of intracellular AChRs. Denervation produces a significant, though less extensive decline in the number of intracellular receptors while having no detectable effect on the number of synaptic AChRs. Small alterations in receptor distribution would have gone undetected by the present techniques. Regulation of neuronal AChRs differs in several respects from that described for muscle AChRs: presynaptic input appears to be less important for controlling neuronal AChRs, while signals from the postsynaptic target tissue may be essential for maintaining synaptic receptors on the neurons.

Regulation of nicotinic acetylcholine receptors (AChRs) on neurons has been studied mainly by electrophysiological means in the past, since molecular probes for reliably distinguishing neuronal AChRs were unavailable. Electrophysiological studies indicated that functional AChRs on neurons are nonuniformly distributed, suggesting a synaptic localization (Harris et al., 1971)

\footnotetext{
Received Oct. 19, 1987; revised Feb. 15, 1988; accepted Feb. 18, 1988.

We thank Dr. Nicholas Spitzer and Dr. Stanley Halvorsen for critical readings of the manuscript and James Johnson for expert technical assistance. Grant support was provided to M.H.J. by the National Institutes of Health (NS 21725) and to D.K.B. by the National Institutes of Health (NS 12601), the Muscular Dystrophy Association, and the American Heart Association with funds contributed in part by the California Heart Association.

Correspondence should be addressed to Dr. Michele H. Jacob, Department of Biology, B-022, University of California, San Diego, La Jolla, CA 92093.

Copyright (C) 1988 Society for Neuroscience $0270-6474 / 88 / 103838-12 \$ 02.00 / 0$
}

as occurs with AChRs in skeletal muscle. Denervation studies produced conflicting reports. Surgical disruption of preganglionic inputs to frog and mudpuppy parasympathetic neurons was found to increase the ACh response of the cells (Kuffler et al., 1971; Roper, 1976, Dennis and Sargent, 1979), as observed for vertebrate skeletal muscle, where denervation induces the appearance of extrajunctional $\mathrm{AChR}$ and increases the total number of AChRs in the tissue (for reviews, see Fambrough, 1979; Schuetze and Role, 1987). Later studies with frog sympathetic neurons, however, found no increase in ACh sensitivity following preganglionic denervation (Dunn and Marshall, 1985). The reason for the different findings with denervated neuronal $\mathrm{ACh}$ sensitivities is unknown. A second type of reported regulation involves signals from the postsynaptic target tissue of neurons: postganglionic axotomy of chick ciliary ganglion neurons has been shown to produce a rapid and specific decline (8-fold reduction in 3-4 d) in the ACh sensitivity of the cells (Brenner and Martin, 1976).

Recently, monoclonal antibody (mAb) and $\alpha$-neurotoxin probes have been used to identify AChRs on autonomic neurons. One of these, $\mathrm{mAb} 35$, is a mAb to the "main immunogenic region" of electric organ and muscle AChR alpha subunits (Tzartos et al., 1981; Barkas et al., 1987) that cross-reacts with neuronal AChRs (Jacob et al., 1984; Smith et al., 1985, 1986; Stollberg et al., 1986; Halvorsen and Berg, 1987). Another is the toxin neuronal-bungarotoxin (n-Bgt), which recognizes the $\mathrm{AChR}$ of chick and rat autonomic neurons (Ravdin and Berg, 1979; Halvorsen and Berg, 1986; Sah et al., 1987) and bovine adrenal chromaffin cells (Higgins and Berg, 1987). n-Bgt has previously been referred to as Bungarotoxin 3.1 , toxin $F$, and $\kappa$-bungarotoxin (Loring and Zigmond, 1988).

Ultrastructural studies with $\mathrm{mAb} 35$ and n-Bgt have demonstrated that AChRs on the surface of chick ciliary ganglion neurons are located predominantly in the synaptic membrane (Jacob et al., 1984; Loring and Zigmond, 1987), corroborating electrophysiological studies implying a synaptic localization for neuronal AChRs. Using radiolabeled $\mathrm{mAb} 35$ to quantitate ganglionic AChRs following surgical disruption of ganglionic connections has produced results that do not fully agree with those inferred from electrophysiological studies. Postganglionic axotomy of ciliary ganglia in newly hatched chicks causes a 10 -fold decline in the total number of ganglionic AChRs within $5 \mathrm{~d}$ (Jacob and Berg, 1987). The rate and extent of decline are consistent with previously reported changes in ACh sensitivities brought on by axotomy of the neurons (Brenner and Martin, 1976). Denervation of ciliary ganglia in newly hatched chicks, however, causes a 3-fold decline in total AChRs (Jacob and Berg, 1987), rather than a maintenance or increase in existing 
receptor levels as might have been inferred from electrophysiological examination of other autonomic systems (Kuffler et al., 1971; Roper, 1976; Dennis and Sargent, 1979; Dunn and Marshall, 1985). It seems unlikely that autonomic neurons of different vertehrate species would respond to denervation in a qualitatively different manner.

A possible explanation for the apparent discrepancy between denervation-induced decreases in total ganglionic AChRs and possible increases in or maintenance of surface AChR levels as detected electrophysiologically emerges from studies of receptor distribution in the neurons. Embryonic ciliary ganglion neurons normally have large numbers of intracellular AChRs (Jacob et al., 1986; Stollberg and Berg, 1987), as does developing muscle both in situ and in vitro (Fambrough and Devreotes, 1978; Atsumi, 1981; Pestronk, 1985). In ciliary ganglion neurons in situ, the intracellular AChRs detected by mAb 35 binding are associated with organelles known to comprise the biosynthetic and regulatory pathways of integral plasma membrane proteins (Jacob ct al., 1986). The organclles include the rough endoplasmic reticulum (RER), the nuclear envelope, Golgi complexes, coated pits, coated vesicles, multivesicular bodies, and smooth-membraned vacuoles. Studies in cell culture indicate that two-thirds of the total AChRs associated with the neurons as detected by ${ }^{125} \mathrm{I}-\mathrm{mAb} 35$ binding are intracellular (Stollberg and Berg, 1987). Accordingly, it is possible that a large decrease in the internal pool of AChRs following denervation could obscure the absence of change or an increase in the number of surface AChRs.

The present study was undertaken to determine the ultrastructural distribution of AChRs in chick ciliary ganglion neurons in situ after preganglionic denervation and after postganglionic axotomy. The results demonstrate that axotomy causes a decline in both the surface and intracellular pools of AChRs, while denervation causes a decrease in the intracellular pool with no detectable change in the surface pool of AChRs.

\section{Materials and Methods}

Operations. Surgical postganglionic axotomy or preganglionic denervation was performed on ciliary ganglia in chicks $2-4 \mathrm{~d}$ after hatching using previously described methods (Jacob and Berg, 1987). For postganglionic axotomy, all of the ciliary and choroid nerves emerging from the ganglion were cut. For preganglionic denervation, the preganglionic input from the Edinger-Westphal (accessory oculomotor) nucleus was severed. Axotomy or denervation was performed on a single ciliary ganglion per chick, preserving the contralateral ganglion as a control. After the operations and recovery from anesthesia, chicks were maintained in a heated brooder for $5 \mathrm{~d}$ following axotomy and $10 \mathrm{~d}$ following denervation. The total absence of a pupillary light reflex was used as a criterion for a successful operation. The ganglion was also examined during dissection to confirm that the appropriate nerves had been completely severed. The success rate of the surgery was approximately $85 \%$.

Light microscopic autoradiography. Light microscopic autoradiography was performed on ganglionic sections labeled with ${ }^{125} \mathrm{I}-\mathrm{mAb} 35$. Operated and unoperated contralateral side ganglia were dissected from the same animals $5 \mathrm{~d}$ after postganglionic axotomy or $10 \mathrm{~d}$ after preganglionic denervation, and were lightly fixcd, frozen, and sectioned on a cryostat as previously described (Jacob et al., 1986). The procedure was modified so that the ganglia and sections were rinsed throughout in PBS containing BSA at $2 \mathrm{mg} / \mathrm{ml}$ (PBS-BSA) (Jacob et al., 1986). The $12-\mu \mathrm{m}$-thick cryostat sections were picked up on poly(L-lysine)-coated slides at room temperature, air-dried at room temperature for $30 \mathrm{~min}$, rinsed several times with PBS-BSA, and air-dried. The sections were then incubated for $1 \mathrm{hr}$ at room temperature in a humid chamber with about $150 \mu \mathrm{l}$ of PBS-BSA containing $10^{-8} \mathrm{M}^{125} \mathrm{I}-\mathrm{mAb} 35$. To evaluate nonspecific labeling, sections were incubated for $20 \mathrm{~min}$ in PBS-BSA containing $10^{-6} \mathrm{M}$ unlabeled $\mathrm{mAb} 35$ and then carried through the normal labeling procedure with ${ }^{125} \mathrm{I}-\mathrm{mAb} 35$ in the continued presence of $10^{-6} \mathrm{M} \mathrm{mAb} 35$. The sections were rinsed 5 times with PBS-BSA, fixed for $30 \mathrm{~min}$ in $4 \%$ glutaraldehyde in PBS, rinsed several times with PBS, and air-dried. The sections were then defatted by rinsing in $95 \%$ ethanol for $5 \mathrm{~min}$, absolute ethanol 3 times for $5 \mathrm{~min}$ each, xylene for 5-10 min, fresh xylene for an additional $30 \mathrm{~min}$, and absolute ethanol 3 times for $5 \mathrm{~min}$ each. The sections were completely air-dried in a dust-free environment. The dried sections were dipped in Kodak NTB-2 autoradiographic emulsion diluted 1:1 with warm Millipore-filtered distilled water. The coated slides were stored in a light-tight microscope box at $4^{\circ} \mathrm{C}$ for approximately $20 \mathrm{hr}$, developed for $3.5 \mathrm{~min}$ at $14^{\circ} \mathrm{C}$ in Kodak D-19, and fixed for $3 \mathrm{~min}$ at $14^{\circ} \mathrm{C}$ in Kodak Rapid Fix. The sections were stained with $1 \%$ toluidine blue and viewed by bright-field microscopy.

Electron microscopy. Electron microscopy was used to examine the distribution of both surface and internal AChRs in ganglion neurons as revealed by the binding of mAb 35 and an HRP-conjugated secondary antibody. For labeling of intracellular AChRs, ganglia were treated as previously described (Jacob et al., 1986). Briefly, the ganglia were lightly fixed, cut into quadrants, detergent-permeabilized with saponin to gain access to intracellular sites, incubated in $\mathrm{mAb} 35$ followed by an HRPconjugated goat anti-rat antibody, fixed, reacted for peroxidase activity, and processed for electron microscopy. For labeling of surface AChRs, ganglia were freshly dissected into aerated $\left(95 \% \mathrm{O}_{2}, 5 \% \mathrm{CO}_{2}\right)$ avian Ringer solution (Ginsborg, 1960), cut into quadrants, and incubated without fixation in $10^{7} \mathrm{M} \mathrm{mAb} 35$ in Ringer solution for $2.5 \mathrm{hr}$ at room temperature with gentle agitation and aeration (Jacob and Berg, 1983; Jacob et al., 1984). The ganglia were then rinsed 3 times for $10 \mathrm{~min}$ each in Ringer solution, incubated in $10^{-6} \mathrm{M} \mathrm{HKP}$-conjugated goat antirat antibody for $2 \mathrm{hr}$, and processed as previously described (Jacob et al., 1986).

Relative levels of intracellular HRP reaction product were assessed in the following manner. Ganglion blocks were trimmed and sectioned so as to include the entire cross-sectional area of the ganglion quadrant in each section. All sections were examined at the same level of magnification on the electron microscope. The neurons in all of the outermost grid squares of the ganglion quadrant cross section were scanned for the presence of HRP reaction product. Selecting the outermost squares ensured adequate penetration of reagents to the region of the ganglion being considered, and established a uniform sampling pool among ganglia. In grid squares where neurons containing HRP reaction product were detected, all of the neurons in that square were evaluated with respect to relative levels of internal HRP reaction product. Four classes of neuronal labeling were established: no, light, moderate, and heavy labeling. Classification was determined predominantly by the proportion of total internal organelles that contained HRP reaction product. The intensity of labeling within the organelles was also evaluated, particularly for "borderline" neurons. In all cases, the RER represented the principal site of intracellular labeling. The classification "no labeling" was reserved for neurons having no detectable intracellular labeling of RER cisternae or other organelles. Neurons were assigned to the "light" category if up to a quarter of the RER cisternae visible in that plane of section of the neuron had detectable reaction product. "Moderate" indicates that between a quarter and three-quarters of the RER cisternae were labeled, while "heavy" indicates three-quarters or more of the RER cisternae were labeled. Assessment of internal HRP reaction product levels was performed on the neurons in the outermost grid squares in each of 4 different axotomized, denervated, and contralateral control ganglia.

The extent of synaptic membrane labeling on the surface of neurons was assessed in the following manner. Ganglion quadrants were incubated with $\mathrm{mAb} 35$ and HRP-conjugated goat anti-rat antibody to label surface AChRs, and the segments were processed and examined by electron microscopy as described above. To ensure that regions selected for analysis had adequate penetration of the reagents, photographs were taken only in those fields of view where at least some synaptic labeling was apparent. In those cases, all of the synaptic membranes were photographed for subsequent analysis. Synaptic membranes in control and axotomized ganglia were distinguished as described previously (Jacob and Berg, 1983; Jacob et al., 1984). In denervated ganglia, the presynaptic terminals were absent, requiring that synaptic membrane be identified solely by postsynaptic cues. These consisted of a straightened and thickened postsynaptic membrane, and an enhanced postsynaptic density (Jacob and Berg, 1983; Jacob et al., 1984). Photography and printing of micrographs were standardized so that micrographs to be compared 
were at the same final magnification and degree of contrast. The extent of HRP reaction product lining the specialized synaptic membranes and the lengths of the specialized surface membranes were then measured directly from the micrographs. For axotomized cases, synaptic membranes were examined in this way for 6 operated ganglia and 5 unoperated contralateral side ganglia used as controls. For denervated cases, 3 operated and 3 unoperated contralateral side ganglia were examined.

Materials. White Leghorn embryonated chick eggs were obtained locally and maintained and hatched at $39^{\circ} \mathrm{C}$ in a humidified incubator. The hybridoma cell line secreting $\mathrm{mAb} 35$ was generously provided by Dr. Jon Lindstrom of the Salk Institute (San Diego, CA). The mAb was purified and radioiodinated by the Chloramine $T$ method to specific activities of $2-3 \times 10^{18} \mathrm{cpm} / \mathrm{mol}$ as previously described (Smith et al., 1985).

\section{Results}

\section{Light microscopic autoradiography}

The effects of postganglionic axotomy and preganglionic denervation on AChR distribution in neurons were first examined at the light microscopic level. Frozen sections were prepared from lightly fixed chick ciliary ganglia $5 \mathrm{~d}$ after axotomy or 10 $\mathrm{d}$ after denervation, and were labeled with ${ }^{125} \mathrm{I}-\mathrm{mAb} 35$ and processed for light microscopic autoradiography. Operated ganglia were taken at these times because previous studies indicated they were sufficient to cause substantial decreases in the total number of AChRs (Jacob and Berg, 1987). Unoperated contralateral ganglia from the same chicks were processed similarly as controls.

Chick ciliary ganglia have nearly equal numbers of choroid and ciliary neurons, the former innervating smooth muscle in the choroid layer and the latter innervating striated muscle in the iris and ciliary body (Landmesser and Pilar, 1974, 1978). Both types of neurons have AChRs that mediate primary chemical synaptic transmission through the ganglion. The ganglion also contains glial cells and preganglionic terminals from the Edinger-Westphal nucleus, which is the sole source of synaptic input to the ganglion (Martin and Pilar, $1963 \mathrm{a}, \mathrm{b}$; Cowan and Wenger, 1968; Landmesser and Pilar, 1978). Autoradiographic grains representing $\mathrm{AChRs}$ were concentrated over the somas of both the ciliary and choroid neurons in all ganglia examined. Few grains were present over neuronal nuclei and processes, and few were associated with other structures in the ganglia such as the non-neuronal cells and preganglionic axons. Unoperated control ganglia had relatively high levels of grains localized over neuronal somas (Fig. 1, $a, d$ ). In contrast, the vast majority of neuronal somas in axotomized ganglia had many fewer grains (Fig. 1b). A few axotomized neurons displayed grain densities more comparable to control neurons. Grain densities over most neuronal somas in denervated ganglia were intermediate between those observed for control and axotomized ganglia; a few denervated neurons had higher grain densities, approaching levels seen with control neurons (Fig. $1 e$ ). In all cases the labeling was specific since incubation with unlabeled mAb 35 before and during the exposure to ${ }^{125} \mathrm{I}-\mathrm{mAb} 35$ resulted in very few grains appearing subsequently (Fig. $1, c, f$ ). Light microscopic autoradiography did not provide sufficient resolution to determine the relative proportions of surface and intracellular AChRs in the operated and control conditions.

\section{Ultrastructural distribution}

Internal AChRs

Ultrastuctural analysis of $A C h R$ distribution was carried out to determine whether the operations preferentially reduced intracellular or surface AChRs. Ganglia $5 \mathrm{~d}$ after postganglionic ax- otomy or $10 \mathrm{~d}$ after preganglionic denervation were lightly fixed and permeabilized by saponin treatment to provide access to internal sites. The permeabilized ganglia were then incubated with mAb 35 followed by HRP-conjugated secondary antibody, reacted for peroxidase activity, and examined with the electron microscope. Again, unoperated contralateral gañglia from the same chicks were processed in parallel as controls.

Both in operated and control ganglia from newly hatched chicks, deposits of HRP reaction product wcre associated with organelles known to comprise the biosynthetic and regulatory pathways for integral plasma membrane proteins. Similar results were previously described for embryonic chick ciliary ganglion neurons (Jacob et al., 1986). The bulk of the intracellular labeling was present on the Nissl bodies or RER of the neurons. The pattern of RER labeling, that is, whether the labeled RER cisternae were dispersed or in clusters throughout the cytoplasm, did not appear to differ in operated and control ganglia. Both configurations of labeled RER cisternae were observed in approximately equal proportions in all ganglia. Reaction product was also present on small portions of the nuclear envelope, some Golgi complexes, and a few coated pits, coated vesicles, multivesicular bodies, and smooth-membraned vacuoles. No other labeling was present in the neurons, and no label was associated with other cell types in the ganglion. In all cases the labeling was specific since substitution of nonimmune rat serum for $\mathrm{mAb}$ 35 at a comparable concentration of immunoglobulin in the initial incubation did not result in significant labeling (Fig. 2, $a, b)$.

Since most of the internal label was associated with the RER, RER labeling was used to compare intracellular levels of AChRs in operated and control ganglia. Within ganglia, variability was encountered in the level and extent of HRP labeling in RER cisternae. In unoperated control ganglion neurons, usually many of the RER cisternae had deposits of HRP reaction product lining the ribosome-studded membranes (Fig. 3, $a, c$ ). In the majority of axotomized neurons only a relatively small proportion of the RER cisternae was labeled (Fig. 3b). In most denervated neurons a greater proportion of the RER cisternae was labeled relative to axotomized neurons, but the levels appeared to be less than in contralateral control neurons (Fig. 3d).

To provide a more quantitative comparison of intracellular AChR levels in operated and control ganglia, neurons were assigned to 1-4 categories on the basis of their HRP labeling. Classification was based predominantly on the proportion of total RER cisternae that contained HRP reaction product in a given plane of section of the neuron. Some consideration was also given to the density of HRP reaction product deposits within the cisternae. Neurons were classified as having no labeling only if their RER cisternae were completely devoid of HRP reaction product, and they had no detectable labeling of any other organelles as well (Fig. 4a). Neurons were classified as lightly labeled if up to a quarter of the RER cisternae contained some HRP reaction product (Fig. 4b). Moderately labeled neurons included those having between one and three-quarters of their RER cisternae labeled (Fig. 4c), while heavily labeled neurons were those having three-quarters or more of their RER cisternae labeled (Fig. 4d). "Borderline" cases were decided on the basis of the relative intensity of HRP labeling within RER cisternae, i.e., if the labeled RER were heavily labeled, the neuron was assigned to the higher of the 2 possible categories. In unoperated control ganglia most of the neurons fell into the light and moderately labeled categories (Fig. 5). A small but signifi- 

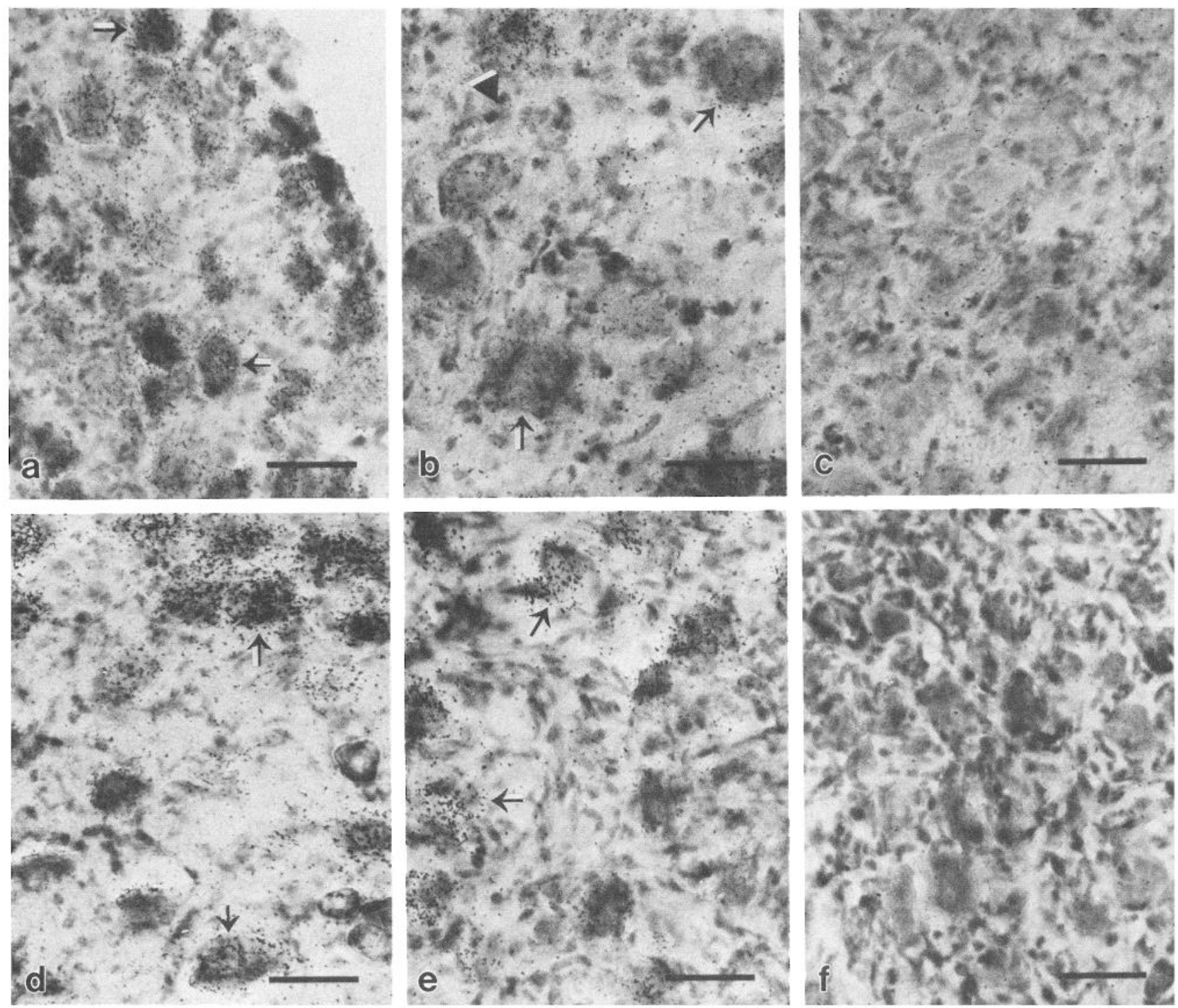

Figure 1. Light microscopic autoradiography of AChR distribution in ciliary ganglion sections. Frozen sections of lightly fixed chick ciliary ganglia after axotomy or denervation were labeled with ${ }^{125} \mathrm{I}-\mathrm{mAb} 35$ and processed for autoradiography. The sections were viewed by bright-field microscopy, and the focal plane was adjusted to reveal grains in the emulsion layer over the neurons. Grains representing ${ }^{125} \mathrm{I}-\mathrm{mAb} 35$ bound to AChR are concentrated over the cytoplasm of neuronal somas (arrows). Few grains are present over neuronal processes and the surrounding small support cells. $a$, Paired control for axotomy: unoperated contralateral ciliary ganglion. $b$, Axotomized ganglion $5 \mathrm{~d}$ after surgery. $c$, Nonspecific labeling: unoperated contralateral ganglion as in $a$, but labeled with ${ }^{125} \mathrm{I}-\mathrm{mAb} 35$ in the presence of a 100 -fold excess of unlabeled mAb 35 . $d$, Paired control for denervation: unoperated contralateral ciliary ganglion. $e$, Denervated ganglion $10 \mathrm{~d}$ after surgery. $f$, Nonspecific labeling: unoperated contralateral ganglion as in $d$ but labeled with ${ }^{125} \mathrm{I}-\mathrm{mAb} 35$ in the presence of a 100-fold excess of unlabeled mAb 35 . Soma labeling is highest for unoperated ganglionic neurons $(a$ and $d)$, moderate for denervated neurons $(e)$, and low for axotomized neurons $(b)$ with a few exceptions $(a r r o w h e a d)$. Scale bars, $100 \mu \mathrm{m}$.

cant proportion of the neurons was heavily labeled. Very few control neurons had no reaction product. Neurons from axotomized ganglia distributed differently among the labeling categories with a clear skew towards categories of lighter labeling compared with that found for control neurons (Fig. $5 A$ ). The number of neurons having no reaction product was significantly increased. The majority of axotomized neurons was lightly labeled, and no neurons were heavily labeled in axotomized ganglia. For denervated ganglia, the distribution of neurons among the labeling categories also displayed a skew towards lighter labeling compared with controls, but the shift was not as extreme as that observed for axotomized ganglia (Fig. 5B). As with axotomized ganglia, no heavily labeled neurons were found in denervated ganglia. Classifying operated and control neurons only on the basis of the relative density of HRP reaction product deposits within labeled RER cisternae led to similar assignments among the 4 labeling categories and resulted in the same relative shifts of operated neurons with respect to control neurons (data not shown).

To evaluate the significance of the labeling shifts, an index of internal labeling was constructed for each ganglion. This involved assigning a numerical value to each of the labeling categories, multiplying each value by the proportion of neurons in the category, and then summing the 4 determinations. Thus, the proportion of neurons in the unlabeled category was multiplied by 1 , the proportion lightly labeled multiplied by 2 , moderately labeled by 3 , and heavily labeled by 4 , and the sum taken as the labeling index. Indices calculated for each of 4 axotomized 

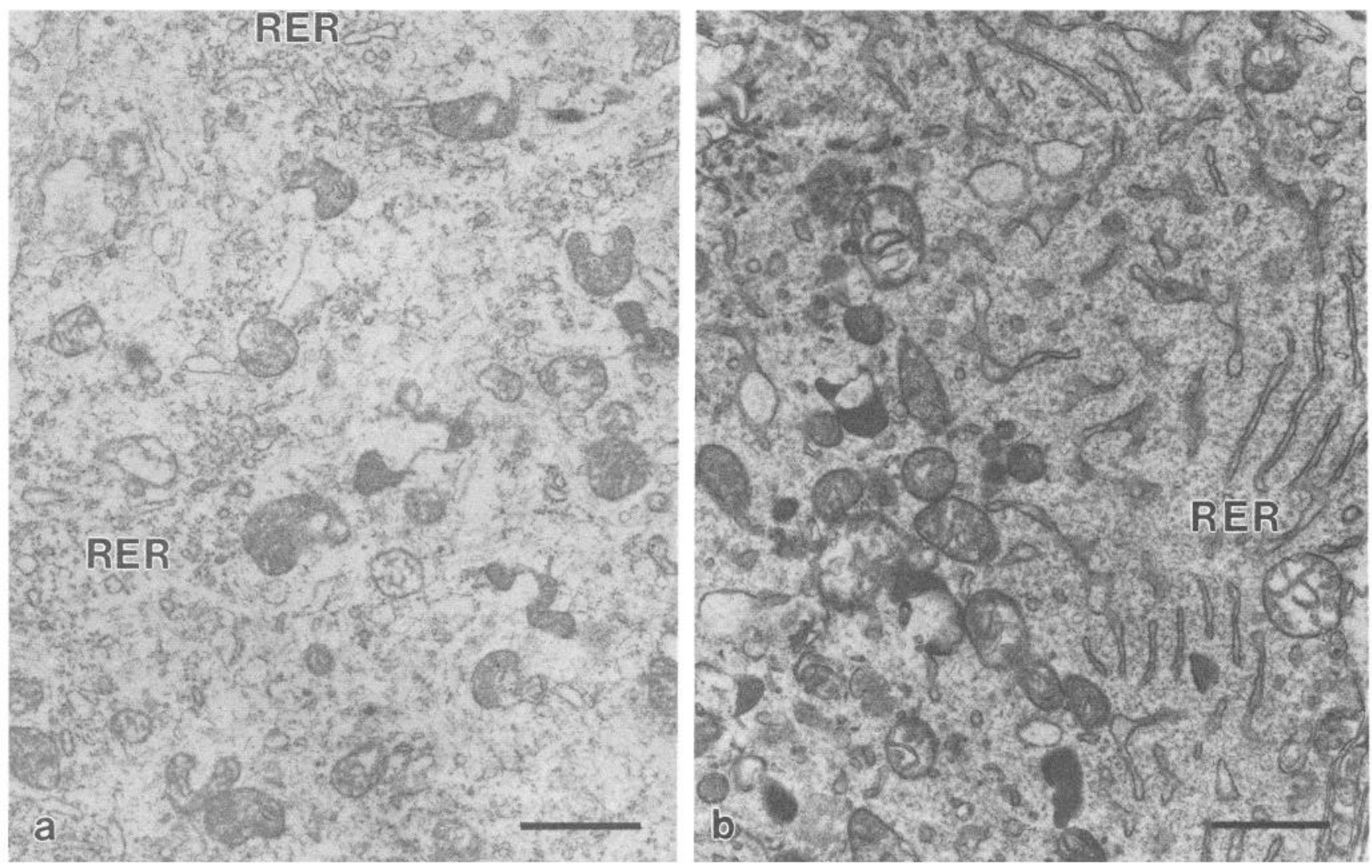

Figure 2. Specificity of intracellular AChR labeling by mAb 35 in ciliary ganglion neurons. Lightly fixed saponin-permeabilized ciliary ganglion quadrants were incubated with nonimmune serum followed by HRP-conjugated secondary antibody and HRP reaction. No labeling is present on the ribosome-studded membranes of the RER cisternae or on any other organelle in the neurons. $a$, Ciliary neuron $5 \mathrm{~d}$ after postganglionic axotomy. $b$, Choroid neuron $10 \mathrm{~d}$ after preganglionic denervation. In the axotomized neuron $a$, the RER cisternae or Nissl bodies are fragmented and dispersed throughout the cytoplasm, displaying a characteristic chromatolytic reaction. In the denervated neuron $b$, individual RER cisternae and numerous ribosomes in polysomal arrays are densely scattered throughout the cytoplasm, displaying the characteristic cytological organization of choroid neurons. The specificity of intracellular labeling in unoperated chick ciliary ganglion neurons has been demonstrated previously in a similar manner (Jacob et al., 1986). Scale bars, $1 \mu \mathrm{m}$.

ganglia and for each of 4 denervated ganglia were lower in every case than any of those calculated for contralateral control ganglia (Table 1). The means of the indices for axotomized ganglia and for denervated ganglia were each significantly lower than the mean index for the respective set of control ganglia (Student's $t$ test, $p<0.005$ ). Though neither axotomy nor denervation qualitatively changed the intracellular distribution of $\mathrm{AChRs,}$ i.e., the types of organelles labeled, each did significantly reduce the size of the intracellular AChR pool in the neurons.

\section{Surface AChRs}

The effects of postganglionic axotomy and preganglionic denervation on the distribution of surface AChRs were examined in chick ciliary ganglia without permeabilization of the tissue so that morphology would be maximally preserved. Freshly dissected, unfixed ganglia were taken from newly hatched chicks $5 \mathrm{~d}$ after axotomy or $10 \mathrm{~d}$ after denervation, cut into quadrants and incubated with $\mathrm{mAb} 35$, followed by HRP-conjugated sec- ondary antibody. After rinsing, the tissues were fixed, reacted for peroxidase activity, and examined with the electron microscope. Unoperated contralateral ganglia from the same chicks were processed in parallel as controls.

In both operated and control ganglia, deposits of HRP reaction product on the ciliary and choroid neuron surfaces were predominantly associated with specialized synaptic membranes as previously observed in embryonic neurons (Jacob et al., 1984, 1986). In no case did the deposits of HRP reaction product at synapses extend along the surface beyond the area of specialized synaptic membrane. Synapses on control and axotomized neurons were readily distinguished by the typical characteristics of a parallel arrangement and thickening of the pre- and postsynaptic membranes, a widened synaptic cleft, an enhanced postsynaptic density, and an accumulation of synaptic vesicles adjacent to the presynaptic membrane (De Lorenzo, 1960; Hess, 1965; Landmesser and Pilar, 1972). Synaptic membrane on denervated neurons could not be distinguished by presynaptic

Figure 3. Ultrastructural distribution of intracellular AChRs in ciliary ganglion neurons. Ganglia were processed as described in the legend of Figure 2, except that the nonimmune serum was replaced with mAb 35 to label the AChRs. $a$, Paired control for axotomy: choroid neuron from unoperated contralateral ciliary ganglion. $b$, Axotomized ciliary neuron $5 \mathrm{~d}$ after surgery. $c$, Paired control for denervation: ciliary neuron from unoperated contralateral ciliary ganglion. $d$, Denervated choroid neuron $10 \mathrm{~d}$ after surgery. In the unoperated control neurons $(a, c)$ many of the 

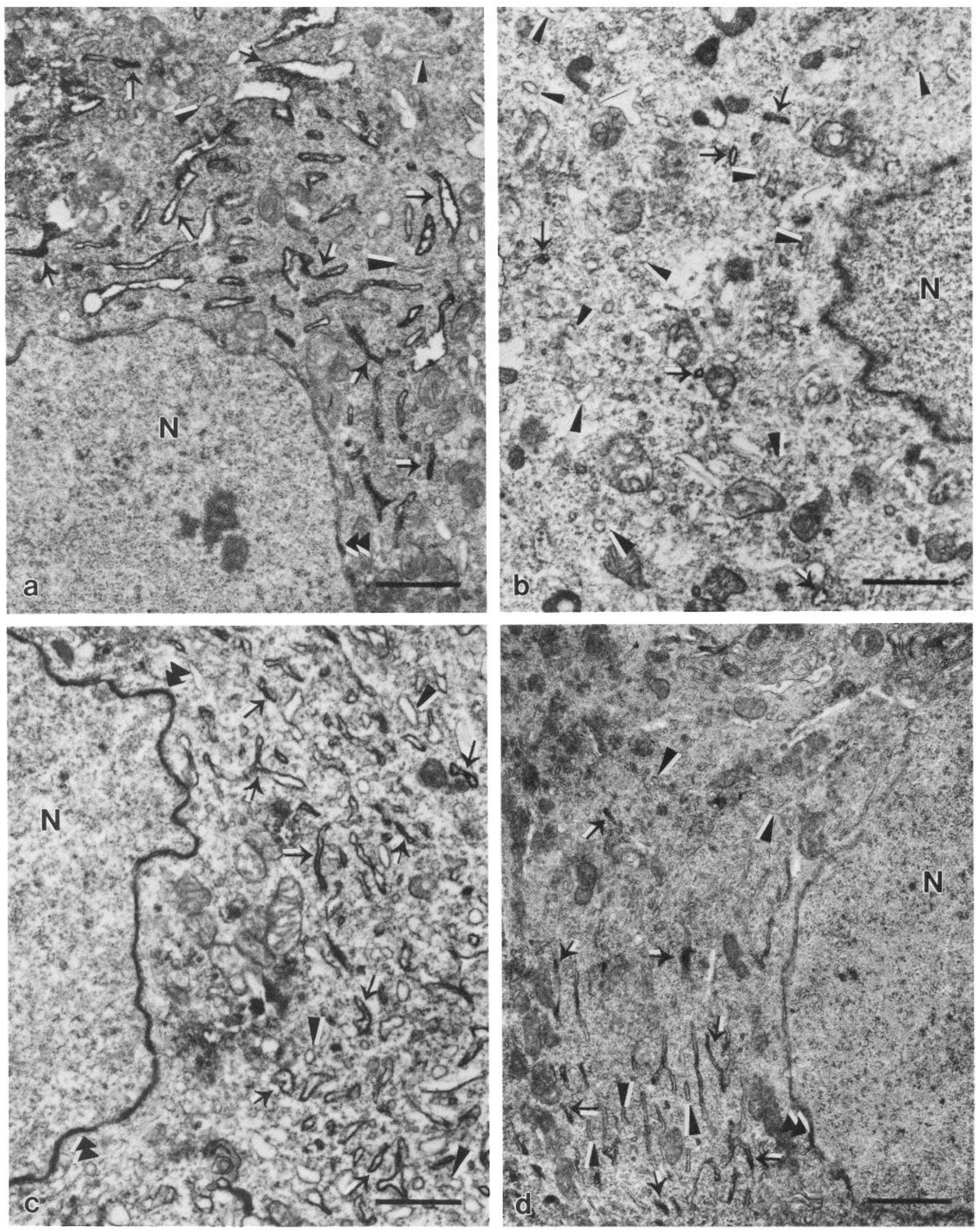

RER cisternae have dense deposits of HRP reaction product (arrows). In the axotomized neuron (b) only a small number of RER cisternae are labeled (arrows). In the denervated neuron $(d)$ an intermediate number of RER cisternae are labeled. RER cisternae lacking reaction product deposits (arrowheads) are also present throughout the cytoplasm in all cases. In addition, small portions of the nuclear envelope (double arrowheads) are occasionally labeled. No label is present within the nuclei $(N)$, and none is associated with mitochondria, free ribosomes, polysomes, or cytoskeletal elements. Scale bars, $1 \mu \mathrm{m}$. 

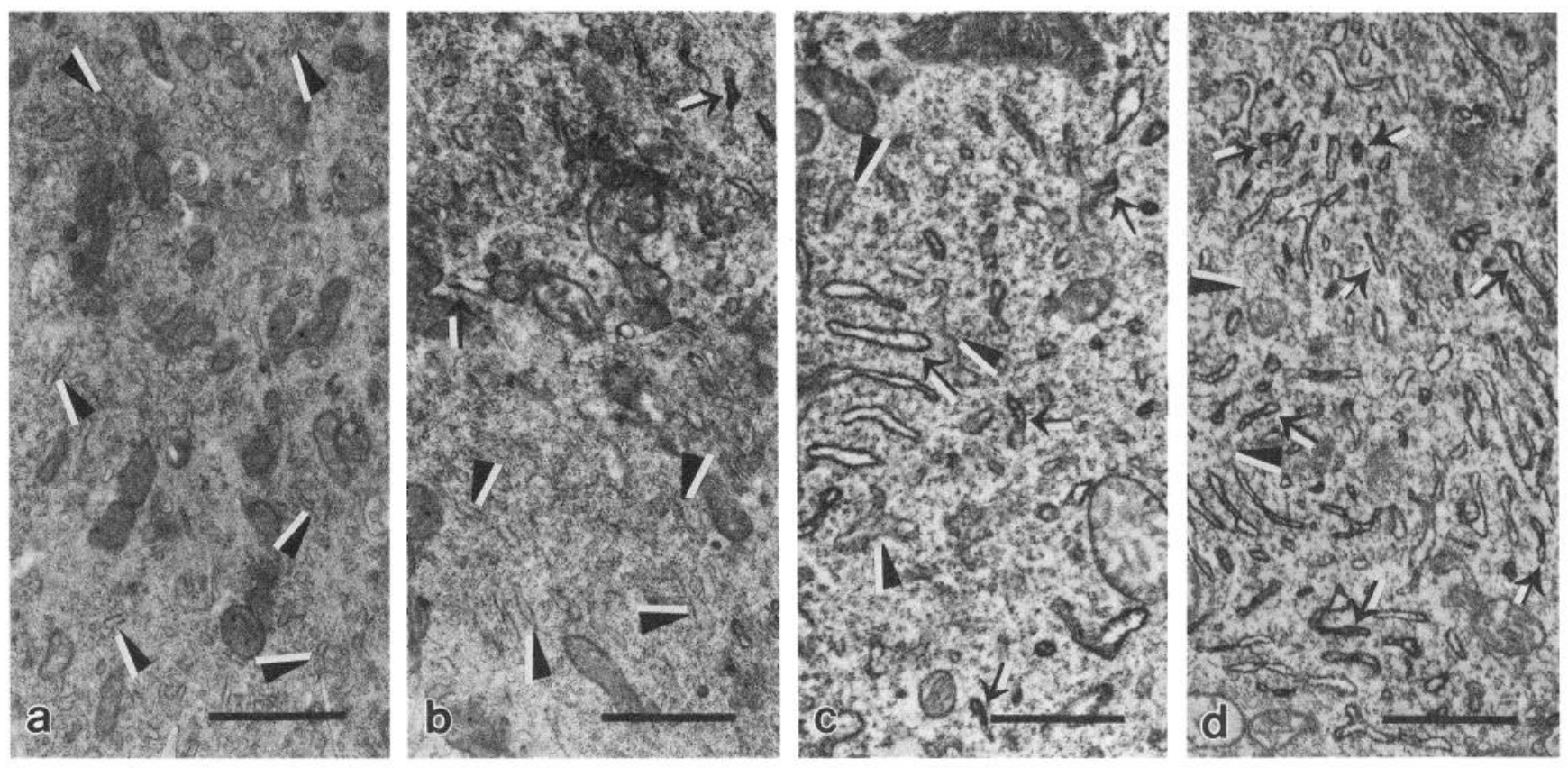

Figure 4. Levels of intracellular AChR labeling. Neurons from ganglia processed, as described in Figure 3, are shown to illustrate the 4 categories of HRP labeling to which neurons were assigned on the basis of the proportion of total RER cisternae containing HRP reaction product and the density of the reaction product deposits within the cisternae. $a$, Axotomized choroid neuron having no HRP reaction product associated with the RER cisternae or any other organelle. Unlabeled RER cisternae are indicated throughout (arrowheads). $b$, Axotomized choroid neuron lightly labeled with less than a quarter of the RER cisternae containing some reaction product (arrows). $c$, Denervated choroid neuron moderately labeled with approximately half of the RER cisternae being labeled (arrows). $d$, Control ciliary neuron heavily labeled with most of the RER cisternae containing dense deposits of HRP reaction product (arrows). Scale bars, $1 \mu \mathrm{m}$.

cues since the preganglionic terminals had degenerated by the time of analysis. In these cases specialized synaptic areas were identified by a straightened and thickened postsynaptic membrane, and an enhanced postsynaptic density; the specialized surface membrane region was opposed by a thin glial cell process or an empty space. In all ganglia, specialized synaptic membrane areas were identified both on the smooth portion of the neuron soma and on the short processes or pseudodendrites that emerge from the postsynaptic cell normally in the region of preganglionic innervation. The only sites of labeling on the neuron surface, other than synaptic membranes, were small portions of the plasma membrane of the numerous pseudodendrites extending out from the neurons in both operated and control ganglia. HRP reaction product was not present on the surface of other cell types in the ganglia. In all cases the surface labeling was specific

\section{Table 1. Index of intracellular HRP labeling}

\begin{tabular}{llllll} 
Ganglion & \multicolumn{2}{l}{ Labeling index } & & Mean \pm SEM \\
\hline Axotomized & 2.2 & 1.88 & 1.72 & 2.02 & $1.96 \pm 0.10$ \\
Paired control & 2.73 & 2.5 & 2.88 & 2.62 & $2.68 \pm 0.08$ \\
Denervated & 2.26 & 2.47 & 2.18 & 2.48 & $2.35 \pm 0.08$ \\
Paired control & 2.63 & 2.76 & 2.57 & 2.77 & $2.68 \pm 0.05$ \\
\hline
\end{tabular}

An index of intracellular labeling was constructed for each of 4 different axotomized, denervated, and paired unoperated contralateral ganglia using the data in Figure 5. Indices were established by summing the values obtained from multiplying the proportion of neurons in each category by the number $(1-4)$ assigned to the category for the respective types of ganglia (see text for details). In all cases, indices calculated for individual operated ganglia are lower than those calculated for any of the unoperated contralateral ganglia. The mean indices obtained for the axotomized and denervated ganglia are each significantly lower than the mean index of their respective contralateral ganglia (Student's $t$ test, $p<0.005$ ). since substitution of nonimmune rat serum for $\mathrm{mAb} 35$ in the initial incubation at an equivalent concentration of immunoglobulin failed to generate detectable HRP reaction product (Fig. $6, a, b)$.

While the localization of AChRs on the neurons did not appear to be altered either by postganglionic axotomy or by preganglionic denervation, the level of surface AChRs was reduced by the former. The degree of synaptic labeling on neurons in axotomized ganglia was less than that observed for neurons in unoperated contralateral ganglia from the same chicks (Fig. 7, $a, b)$. The proportion of the surface membrane lined by HRP reaction product on pseudodendrites was also reduced following axotomy. Both the synaptic membranes (Fig. 7, $c, d$ ) and the surface membranes of pseudodendrites (not shown) on neurons in denervated ganglia appeared to be labeled to the same extent as neurons from contralateral control ganglia.

To provide a more quantitative comparison of synaptic labeling for operated and control neurons, the length of reacted surface membrane within individual specialized synaptic areas was measured and compared with the total length of specialized synaptic membrane at the same site. This approach was taken in lieu of measuring the thickness of the reaction product layer associated with the specialized synaptic membrane because of variability in the layer thickness within individual synapses and because of the influence on the buildup of reaction product deposits imposed by the physical constraints of the cleft space. Examination of the length of synaptic labeling indicated that neurons in axotomized ganglia had equivalent lengths of specialized synaptic membranes to those found in control ganglia, but the proportion of the length having label was reduced by nearly a factor of 2 (Table 2). Neurons in denervated ganglia showed no change in the mean length of specialized synaptic 


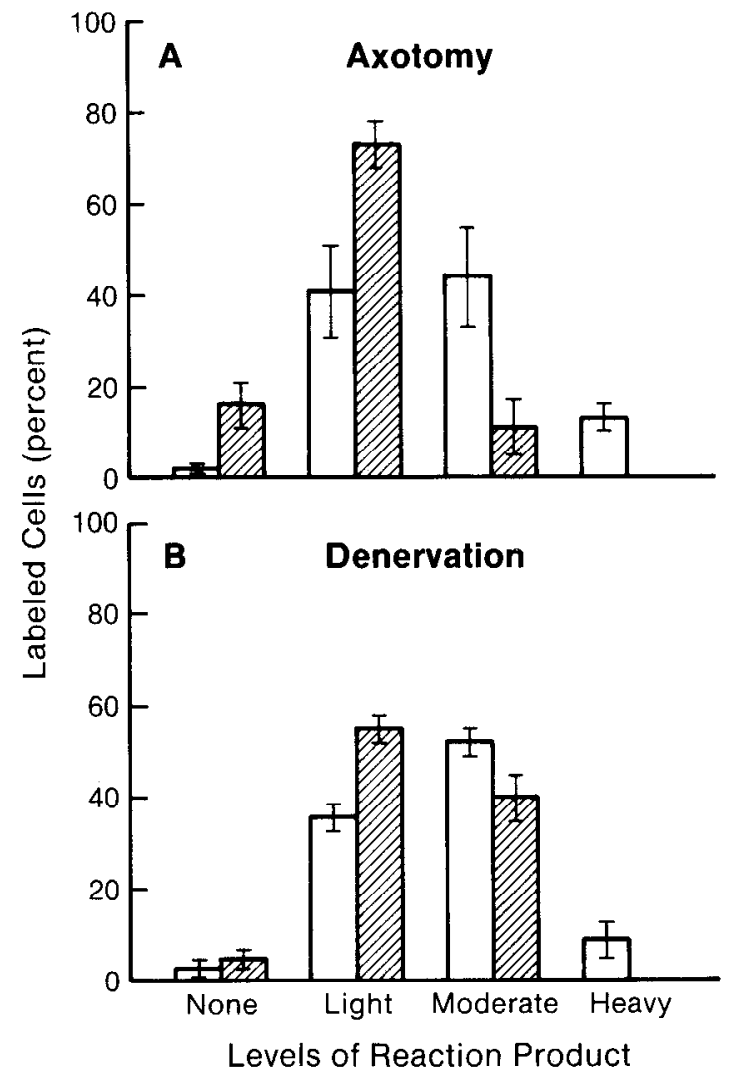

Figure 5. Distribution of neurons among the labeling categories for intracellular AChRs. Neurons from ganglia processed, as described in Figure 3 , were assigned to the 4 categories of labeling for intracellular AChRs. The results are expressed as the percentage of total neurons classified within each ganglion. Each determination represents the mean \pm SEM of neurons from 4 different axotomized, denervated, or paired unoperated contralateral ganglia. $A$, Axotomy: a total of 139 operated neurons (hatched bars) and 181 unoperated neurons (open bars) are represented. $B$, Denervation: a total of 136 operated neurons (hatched bars) and 196 unoperated neurons (open bars) are represented.

membrane or in the proportion of the length labeled with HRP reaction product compared with neurons from unoperated contralateral ganglia (Table 2). By this criterion postganglionic axotomy appears to reduce the number of surface AChRs on the neurons, while preganglionic denervation has little effect on the surface pool.

\section{Discussion}

The present findings demonstrate that postganglionic axotomy of chick ciliary ganglia produces a substantial decrease both in the size of the intracellular pool of AChRs and in the pool of synaptic AChRs on the neurons. Preganglionic denervation reduces the intracellular pool to a smaller extent and has little, if any, effect on the number of synaptic AChRs. The results suggest that both surface and internal AChRs are subject to regulation by one or more types of cell-cell interactions.

Quantitation of AChR pools at the ultrastructural level is not possible with HRP labeling because the amount of HRP reaction product cannot be quantitatively measured and because the relationship between the amount of reaction product and the density of AChRs may be complex. Reaction conditions were chosen to give readily identifiable, distinct deposits of reaction product in control ganglia, rather than being adjusted to achieve linearity between receptor number and formation of reaction
Table 2. Extent of synaptic HRP labeling

\begin{tabular}{llll} 
& $\begin{array}{l}\text { Length of } \\
\text { synaptic } \\
\text { reaction } \\
\text { product } \\
(\mu \mathrm{m})\end{array}$ & $\begin{array}{l}\text { Length of } \\
\text { synapse } \\
(\mu \mathrm{m})\end{array}$ & $\begin{array}{l}\text { Propor- } \\
\text { tion of } \\
\text { synaptic } \\
\text { length } \\
\text { labeled } \\
(\%)\end{array}$ \\
\hline Ganglion & $0.25 \pm 0.03$ & $0.51 \pm 0.04$ & $47 \pm 3$ \\
\hline Axotomized & $0.39 \pm 0.03$ & $0.45 \pm 0.03$ & $84 \pm 3$ \\
Paired Control & $0.30 \pm 0.03$ & $0.36 \pm 0.03$ & $86 \pm 3$ \\
Denervated & $0.35 \pm 0.04$ & $0.41 \pm 0.04$ & $84 \pm 4$ \\
Paired Control & 0.04
\end{tabular}

The length of reacted surface membrane within individual specialized synaptic areas was measured and compared with the total length of the specialized synaptic membrane at the same site on the neuron surface. The values represent the mean \pm SEM of measurements taken from 35 synapses on neurons from 6 axotomized ganglia together with 54 synapses on unoperated neurons from 5 of the paired contralateral ganglia, and 41 synaptic membranes on neurons from 3 denervated ganglia together with 17 synapses on unoperated neurons from their 3 paired contralateral ganglia. The mean length of specialized synaptic membranes both on axotomized and on denervated neurons is similar to that on unoperated neurons. The proportion of synaptic length that is labeled on axotomized neurons is significantly lower than on unoperated neurons (Student's $t$ test, $p<0.005$ ); no difference in extent of synaptic labeling was observed between denervated and unoperated neurons.

precipitate. Nevertheless, we have attempted a semiquantitative comparison of HRP labeling in operated and control ganglia by measuring the length of HRP reaction product lining synaptic profiles in the case of surface receptors and by determining the proportion of RER cisternae having at least some reaction product in the case of intracellular receptors.

While identification of synapses is reasonably straightforward on control and axotomized neurons, distinguishing such sites on denervated neurons is complicated by the absence of cues normally provided by the presynaptic terminal. Most useful in this latter case are the straightened and thickened postsynaptic membrane and the associated postsynaptic density which persist throughout the time period examined in the present study (Sotelo, 1968; Westrum, 1969; Raisman et al., 1974). In contrast, postganglionic axotomy may eliminate synaptic contacts in an all-or-none manner. Brenner and Johnson (1976) have reported that axotomy of ciliary ganglia in newly hatched chicks increases the neuronal surface area devoid of contact by presynaptic terminals by about $16 \%$ at $3 \mathrm{~d}$ and by about $27 \%$ at 9 d. Postsynaptic membrane specializations are apparently not retained on axotomized neurons following loss of the presynaptic terminal (Matthews and Nelson, 1975; Purves, 1975). In the present study all of the synaptic membranes used to evaluate HRP labeling in axotomized ganglia were juxtaposed to presynaptic terminals.

Changes in the number of surface AChRs inferred here are in remarkable agreement with those inferred from electrophysiological measurements. Chick ciliary ganglion ncurons axotomized for 3-4 d display an $80 \%$ reduction in ACh sensitivity compared with control neurons (Brenner and Martin, 1976). Nearly a $50 \%$ decline was observed here in the mean length of HRP reaction product coating synaptic membrane on neurons from ganglia axotomized for $5 \mathrm{~d}$. Considering that synaptic area would be proportional to the square of the length measured as a synaptic profile, one calculates an expected decline in synaptic AChRs of approximately $75 \%$. The lack of change in HRP labeling of synaptic membrane on denervated neurons is also consistent with electrophysiological studies showing no change in ACh sensitivity following denervation of frog sympathetic 

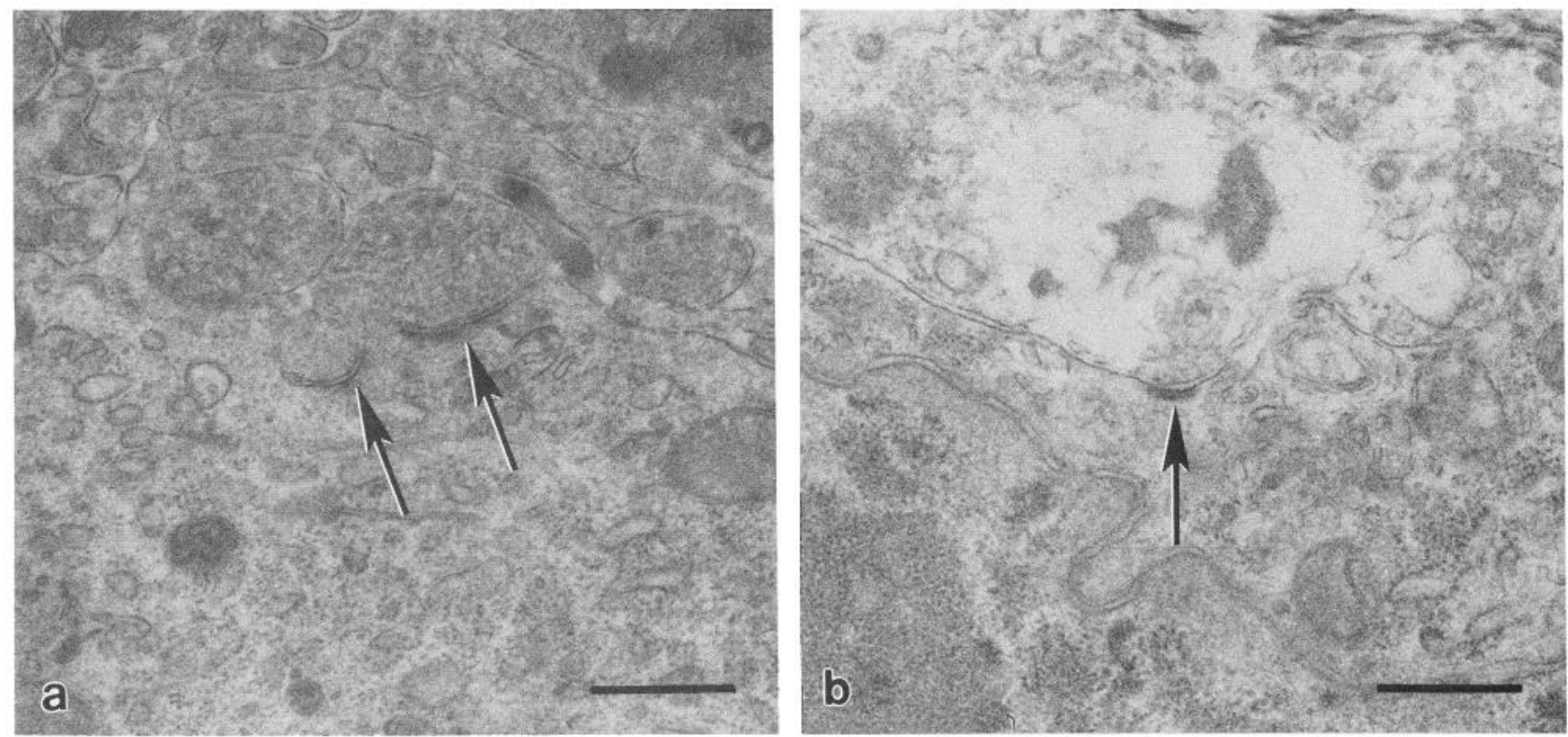

Figure 6. Specificity of labeling surface AChRs on ciliary ganglion neurons with mAb 35 . Freshly dissected, unfixed ciliary ganglia were cut into quadrants, incubated with nonimmune serum without saponin permeabilization, and were processed for detection of antibody binding by electron microscopy as described in Figure 2. $a$, Choroid neuron $5 \mathrm{~d}$ after postganglionic axotomy. $b$, Choroid neuron $10 \mathrm{~d}$ after preganglionic denervation. Specialized synaptic membranes are not labeled and label is not present elsewhere on the neuron surface. On the axotomized neuron $(a)$ the synapse (arrow) is distinguished by a parallel arrangement and thickening of the pre- and postsynaptic membranes, a widened synaptic cleft, an enhanced postsynaptic density, and an accumulation of synaptic vesicles adjacent to the presynaptic membrane. On the denervated neuron $(b)$ the specialized synaptic area (arrow) is distinguished by a thickened postsynaptic membrane and an enhanced postsynaptic density. The specialized membrane is opposed by a region of presynaptic terminal degeneration. Specificity of surface labeling has been demonstrated previously with unoperated chick ciliary ganglion neurons (Jacob et al., 1986). Scale bars, $0.5 \mu \mathrm{m}$.

neurons (Dunn and Marshall, 1985). Preliminary results suggest that denervation also fails to alter the ACh sensitivity of chick ciliary ganglion neurons (A. McEachern and M. Jacob, unpublished observations). Denervated frog sympathetic neurons retain a nonuniform distribution of ACh sensitivity as found on control neurons (Dunn and Marshall, 1985), suggesting that extrasynaptic AChRs either do not exist on denervated neurons or remain in low abundance. In the present study, the only labeling found on the neuron surface outside of the specialized synaptic membranes was small patches of labeling on pseudodendrites. The extent of such labeling was roughly comparable for operated and control ganglia, but the complex contour of the membrane in these regions and the limited amounts of labeling prohibited a more quantitative comparison. No evidence for additional extrasynaptic AChRs was found, although the appearance of such sites, either through de novo synthesis or through migration of existing surface receptors, might occur following disruption of ganglionic connections but remain below the limits of detection by the HRP-labeling method. Synaptic AChRs, which have been estimated to be present at $600 / \mu \mathrm{m}^{2}$ on chick ciliary ganglion neurons (Loring and Zigmond, 1987), are clearly detectable by the method. Extrajunctional AChRs on embryonic chick skeletal muscle, estimated at $250 / \mu \mathrm{m}^{2}$ (Burden, 1977), were not detectable by HRP labeling though in this case HRP was coupled directly to the primary ligand (Jacob and Lentz, 1979), which would not have permitted the type of signal amplification obtained here using an HRP-conjugated secondary antibody. HRP reaction product might also be lost more easily from the exposed extrajunctional regions of muscle than from the neuron surface which is completely encapsulated by glial cells. In any case, it is clear that for detection of possible low levels of extrasynaptic $\mathrm{AChRs}$ and for quantitation of changes in synaptic AChRs on the neurons brought about by the disruption of ganglionic connections, a more sensitive and quantitative method of receptor assay will be required.

It is of interest that preganglionic denervation significantly reduced intracellular AChRs without having a detectable effect on synaptic AChRs. Studies in cell culture indicate that twothirds or more of the total AChRs associated with ciliary ganglion neurons are intracellular and that only a few percent of them are destined to be expressed on the cell surface (Stollberg and Berg, 1987). Ciliary ganglion neurons in situ have also been shown to have large populations of intracellular AChRs (Jacob et al., 1986). Accordingly, it is possible that a substantial change in the internal pool of AChRs could occur in response to denervation without dramatically influencing the subpopulation supplying the cell surface. Precedence for this comes from rat skeletal muscle, where large decreases in the number of intracellular AChRs occur over time without being accompanied by proportionate changes in the number of surface AChRs (Pestronk, 1985). Similarly, the number of intracellular $\alpha$-subunits of the voltage-dependent $\mathrm{Na}^{+}$channel found in rat brain cells diminishes substantially during late development without a corresponding change in the level of $\mathrm{Na}^{+}$channels on the cell surface (Schmidt et al., 1985).

Axotomy induces a $90 \%$ decrease in the total number of AChRs in the ganglion within $5 \mathrm{~d}$ (Jacob and Berg, 1987). Correcting for cell loss $(37 \%)$ predicts a 6 -fold decline in the number of receptors associated with the remaining neurons. If three-quarters of the surface receptors are lost and they initially represented a third of the total receptors, one calculates by difference that intracellular AChRs in the surviving neurons should have de- 

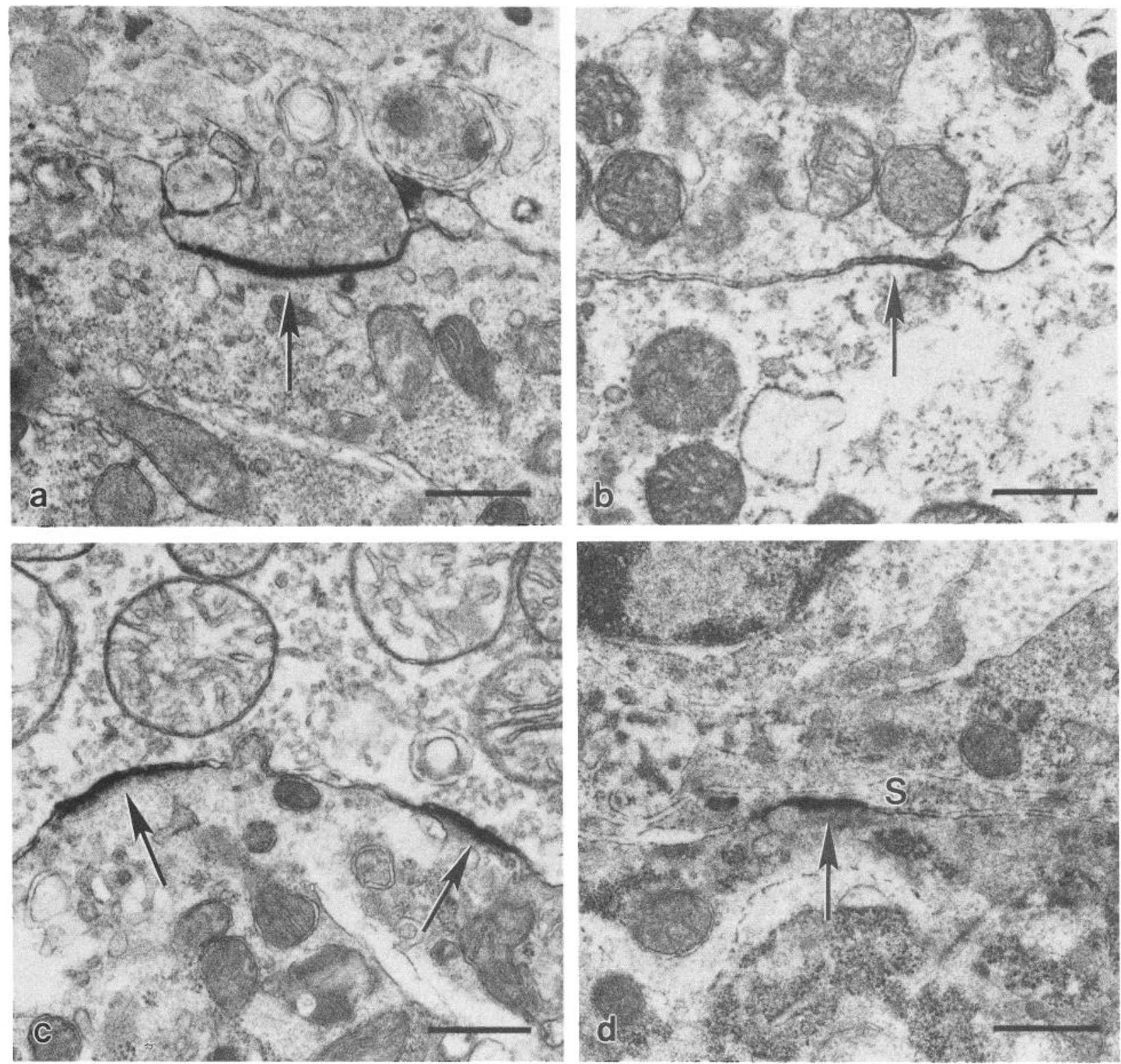

Figure 7. Ultrastructural distribution of AChRs on the surface of ciliary ganglion neurons. Ganglia were processed, as described in Figure 6, with the nonimmune serum being replaced with mAb 35 to label the AChRs. $a$, Paired control for axotomy: choroid neuron from unoperated contralateral ciliary ganglion. $b$, Axotomized ciliary neuron $5 \mathrm{~d}$ after surgery. $c$, Paired control for denervation: choroid neuron from unoperated contralateral ciliary ganglion. $d$, Denervated choroid neuron $10 \mathrm{~d}$ after surgery. Surface labeling is predominantly associated with the specialized synaptic membranes. HRP labeling does not extend along the surface beyond the area of specialized synaptic membrane. On unoperated neurons ( $a, c)$ dense deposits of HRP reaction product fill the clefts along almost the entire length of the specialized synaptic areas (arrows) present on the smooth portion of the neuronal somata. On the axotomized neuron $(b)$ only a small portion of the synaptic membrane (arrow) is labeled. On the denervated neuron $(d)$ HRP reaction product extends along almost the entire length of the specialized synaptic membrane (arrow), filling the space between the postsynaptic neuron and the opposing Schwann cell process $(S)$. Scale bars, $0.5 \mu \mathrm{m}$.

clined at least 10 -fold. Denervated ganglia do not exhibit significant cell loss during the first $10 \mathrm{~d}$, and the approximately 3-fold decrease in total AChRs observed during this period (Jacob and Berg, 1987) can be attributed largely to a decline in intracellular receptors. Again, if surface AChRs represented a third of the original total and remained unchanged in number, then the 3-fold decline in total receptors would predict a nearly complete loss of intracellular receptors. Declines of this magnitude did not appear to be the case either for denervated or axotomized neurons. The most likely explanation has to do with the procedures used here to estimate decreases in receptor number which would probably produce underestimates for several reasons. Foremost among these is the possibility of nonlinearity between receptor density and reaction product as mentioned previously. If the control conditions represented a saturation of the assay, then large declines in receptor density might produce only small reductions in reaction product deposits, and small declines in receptor number would go undetected. A second consideration comes from the fact that fields of view were selected for analysis only if they contained at least some labeling. This was necessary to ensure that the labeling reagents had penetrated the region being analyzed. While an important precaution, the selection procedure would be expected to skew the data towards higher levels of labeling in cases where little or no 
labeling represented the norm. Together these factors could have obscured small declines in receptor number, e.g., in the case of surface AChRs on denervated neurons, or could have converted large decreases into small shifts in degree of labeling when examined by the present procedures.

Using RER labeling to evaluate relative levels of intracellular receptors requires that the RER itself be comparable under the various test conditions. Axotomized chick ciliary neurons undergo a characteristic chromatolytic reaction that includes fragmentation and dispersal or peripheral displacement of the Nissl substance (Koenig, 1965; Pilar and Landmesser, 1972). There is no apparent change in the distribution of RER within choroid neurons in response to axotomy: individual RER cisternae remain densely scattered throughout the cytoplasm. Postganglionic axotomy of young adult rat superior cervical ganglia produces a reversible reduction in the amount of Nissl substance during the first $2 \mathrm{~d}$ (Matthews and Raisman, 1972). No such chromatolytic changes occur in response to preganglionic denervation of adult rabbit superior cervical ganglia (Hamlyn, 1954). In the present study, no gross degenerative changes were observed in surviving neurons of operated ganglia at any of the times examined. When evaluating HRP labeling of RER, all the RER in the plane of section of the neuron was included so that a dispersal induced by axotomy or denervation would not itself alter the pool being sampled. A final consideration concerns possible dislocation of HRP reaction product, e.g., through diffusion (Novikoff et al., 1972). Since the RER cisternae represent enclosed spaces, loss or movement of reaction product should have been minimized (Willingham, 1980).

The changes in neuronal AChR pools brought on by disruption of ganglionic connections imply quite different regulatory controls from those operating on muscle AChRs. Denervation of skeletal muscle induces a large increase in the total number of AChRs, primarily through an accumulation of extrajunctional receptors on the surface (for reviews, see Salpeter, 1987; Schuetze and Role, 1987). These alterations are known to be mediated by changes in muscle activity under the control of the presynaptic nerve. Denervation of chick ciliary ganglion neurons was previously shown to reduce the total number of receptors in the ganglion (Jacob and Berg, 1987), but the present studies detected no obvious effect of denervation on the number or distribution of surface AChRs. Admittedly, small changes would have gone unnoticed by the present methods. Either preganglionic denervation has little impact on neuronal activity in vivo, or, more likely, neuronal AChRs are not regulated by cellular activity in the same manner as muscle AChRs. The finding that postganglionic axotomy reduces both internal and surface pools of neuronal AChRs suggests that information from the postsynaptic target tissue is required both to sustain the large intracellular pool of AChRs in the neurons and to maintain normal levels of synaptic AChRs. Presynaptic input also appears to play a role in maintaining the internal pool of $\mathrm{AChRs}$, but its effects on surface AChR levels are less significant. Regulation of symaptic AChRs on neurons by signals from the target tissue would have obvious value for ensuring proper functional innervation of the end organ.

\section{References}

Atsumi, S. (1981) Localization of surface and internal acetylcholine receptors in developing fast and slow muscles of the chick embryo. Dev. Biol. 86: 122-135.

Barkas, T., A. Mauron, B. Roth, C. Alliod, S. J. Tzartos, and M. Ballivet
(1987) Mapping the main immunogenic region and toxin-binding site of the nicotinic acetylcholine receptor. Science $235: 77-80$.

Brenner, H. R., and E. W. Johnson (1976) Physiological and morphological effects of post-ganglionic axotomy on presynaptic nerve terminals. J. Physiol. (Lond.) 260: 143-158.

Brenner, H. R., and A. R. Martin (1976) Reduction in acetylcholine sensitivity of axotomized ciliary ganglion cells. J. Physiol. (Lond.) 260: 159-175.

Burden, S. (1977) Development of the neuromuscular junction in the chick embryo: The number, distribution, and stability of acetylcholine receptors. Dev. Biol. 57: 317-329.

Cowan, W. M., and E. Wenger (1968) Degeneration in the nucleus of origin of the preganglionic fibers to the chick ciliary ganglion following early removal of the optic vesicle. J. Exp. Zool. 168: 105-124.

De I corenzo, A. J. (1960) The fine structure of synapses in the ciliary ganglion of the chick. J. Biophys. Biochem. Cytol. 7: 31-36.

Dennis, M. J., and P. B. Sargent (1979) Loss of extrasynaptic acetylcholine sensitivity upon reinnervation of parasympathetic ganglion cells. J. Physiol. (Lond.) 289: 263-275.

Dunn, P. M., and L. M. Marshall (1985) Lack of nicotinic supersensitivity in frog sympathetic neurones following denervation. J. Physiol. (Lond.) 363: 211-225.

Fambrough, D. M. (1979) Control of acetylcholine receptors in skeletal muscle. Physiol. Rev. 59: 165-227.

Fambrough, D. M., and P. N. Devreotes (1978) Newly synthesized acetylcholine receptors are located in the Golgi apparatus. J. Cell Biol. 76: 237-244.

Ginsborg, B. L. (1960) Spontaneous activity in muscle fibres of the chick. J. Physiol. (Lond.) 150:707-717

Halvorsen, S. W., and D. K. Berg (1986) Identification of a nicotinic acetylcholine receptor on neurons using an $\alpha$-neurotoxin that blocks receptor function. J. Neurosci. 6: 3405-3412.

Halvorsen, S. W., and D. K. Berg (1987) Affinity labeling of neuronal acetylcholine receptor subunits with an $\alpha$-neurotoxin that blocks receptor function. J. Neurosci. 7: 2547-2555.

Hamlyn, L. H. (1954) The effect of preganglionic section on the neurons of the superior cervical ganglion in rabbits. J. Anat. $88: 184$ 193.

Harris, A. J., S. W. Kuffler, and M. J. Dennis (1971) Differential chemosensitivity of synaptic and extrasynaptic areas on the neuronal surface membrane in parasympathetic neurons of the frog, tested by microapplication of acetylcholine. Proc. R. Soc. London [Biol.] 177: 541-553.

Hess, A. (1965) Developmental changes in the structure of the synapse on the myelinated cell bodies of the chicken ciliary ganglion. J. Cell Biol. 25: 1-19.

Higgins, L. S., and D. K. Berg (1987) Immunological identification of a nicotinic acetylcholine receptor on bovine chromaffin cells. J. Neurosci. 7: 1792-1798.

Jacob, M. H., and D. K. Berg (1983) The ultrastructural localization of $\alpha$-bungarotoxin binding sites in relation to synapses on chick ciliary ganglion neurons. J. Neurosci. 3: 260-271.

Jacob, M. H., and D. K. Berg (1987) Effects of preganglionic denervation and postganglionic axotomy on acetylcholine receptors in the chick ciliary ganglion. J. Cell Biol. 105: 1847-1854.

Jacob, M., and T. L. Lentz (1979) Localization of acetylcholine receptors by means of horseradish peroxidase- $\alpha$-bungarotoxin during formation and development of the neuromuscular junction in the chick embryo. J. Cell Biol. 82: 195-211.

Jacob, M. H., D. K. Berg, and J. M. Lindstrom (1984) A shared antigenic determinant between the Electrophorus acetylcholine receptor and a synaptic component on chick ciliary ganglion neurons. Proc. Natl. Acad. Sci. USA 81: 3223-3227.

Jacob, M. H., J. M. Lindstrom, and D. K. Berg (1986) Surface and intracellular distribution of a putative neuronal acetylcholine receptor. J. Cell Biol. 103: 205-214.

Koenig, H. L. (1965) Relations entre la distribution de l'activité acetylcholinesterasique et celle de l'ergastoplasme dans les neurones du ganglion ciliaire du poulet. Arch. Anat. Microsc. Morphol. Exp. 54: 937-964.

Kuffler, S. W., M. J. Dennis, and A. J. Harris (1971) The development of chemosensitivity in extrasynaptic areas of the neuronal surface after denervation of parasympathetic ganglion cells in the heart of the frog. Proc. R. Soc. London [Biol.] 177: 555-563.

Landmesser, L., and G. Pilar (1972) The onset and development of 
transmission in the chick ciliary ganglion. J. Physiol. (Lond.) 222: 691-713.

Landmesser, L., and G. Pilar (1974) Synapse formation during embryogenesis on ganglion cells lacking a periphery. J. Physiol. (Lond.) 241: 715-736.

I andmesser, L., and G. Pilar (1978) Interactions between neurons and their targets during in vivo synaptogenesis. Fed. Proc. 37: 2016-2022.

Loring, R. H., and R. E. Zigmond (1987) Ultrastructural distribution of ${ }^{125}$ I-toxin $F$ binding sites on chick ciliary ncurons: Synaptic localization of a toxin that blocks ganglionic nicotinic receptors. J. Neurosci. 7: 2153-2162.

Loring, R. H., and R. E. Zigmond (1988) Characterization of neuronal nicotinic receptors by snake venom neurotoxins. TINS 11: 73-78.

Martin, A. R., and G. Pilar (1963a) Dual mode of synaptic transmission in the avian ciliary ganglion. J. Physiol. (Lond.). 168: 443-463.

Martin, A. R., and G. Pilar (1963b) Transmission through the ciliary ganglion of the chick. J. Physiol. (Lond.). 168: 464-475.

Matthews, M. R., and V. H. Nelson (1975) Detachment of structurally intact nerve endings from chromatolytic neurones of rat superior cervical ganglion during the depression of synaptic transmission induced by postganglionic axotomy. J. Physiol. (Lond.) 245: 91-135.

Matthews, M. R., and G. Raisman (1972) A light and electron microscopic study of the cellular response to axonal injury in the superior cervical ganglion of the rat. Proc. R. Soc. London [Biol.] 181: 43-79.

Novikoff, A. B., P. M. Novikoff, N. Quintana, and C. Davis (1972) Diffusion artifacts in 3,3'-diaminobenzidine cytochemistry. J. Histochem. Cytochem. 20: 745-749.

Pestronk, A. (1985) Intracellular acetylcholine receptors in skeletal muscles of the adult rat. J. Neurosci. 5: 1111-1117.

Pilar, G., and L. Landmesser (1972) Axotomy mimicked by localized colchicine application. Science (Wash. D.C.). 177: 1116-1118.

Purves, D. (1975) Functional and structural changes in mammalian sympathetic neurones following interruption of their axons. J. Physiol. (I ond.) 252: 429-463.

Raisman, G., P. M. Field, A. J. C. Ostberg, L. L. Iversen, and R. E. Zigmond (1974) A quantitative ultrastructural and biochemical analysis of the process of reinnervation of the superior ccrvical ganglion in the adult rat. Brain Res. 71: 1-16.

Ravdin, P. M., and D. K. Berg (1979) Inhibition of neuronal acetylcholine sensitivity by $\alpha$-toxins from Bungarus multicinctus venom. Proc. Natl. Acad. Sci. USA 76: 2072-2076.

Roper, S. (1976) The acetylcholine sensitivity of the surface membrane of multiply-innervated parasympathetic ganglion cells in the mudpuppy before and after partial denervation. J. Physiol. (Lond.) 254: $455-473$.

Sah, D. W. Y., R. H. Loring, and R. E. Zigmond (1987) Long-term blockade of nicotinic synaptic potentials in cultured sympathetic neurons. Neuroscience 20: 867-874.

Salpeter, M. M. (1987) Development and neural control of the neuromuscular junction and of the junctional acetylcholine receptor. In The Vertebrate Neuromuscular Junction, M. M. Salpeter, ed., pp. 55115 , Liss, New York.

Schmidt. J., S. Rossie, and W. A. Catterall (1985) A large intracellular pool of inactive $\mathrm{Na}$ channel alpha subunits in developing rat brain. Proc. Natl. Acad. Sci. USA 82: 4847-4851.

Schuetze, S. M., and L. W. Role (1987) Developmental regulation of the nicotinic acetylcholine receptor. Annu. Rev. Neurosci. 10: 403457.

Smith, M. A., J. Stollberg, J. M. Lindstrom, and D. K. Berg (1985) Characterization of a component in chick ciliary ganglia that crossreacts with monoclonal antibodies to muscle and electric organ acetylcholine receptor. J. Neurosci. 5: 2726-2731.

Smith, M. A., J. F. Margiotta, A. Franco, Jr., J. M. Lindstrom, and D. K. Berg (1986) Cholinergic modulation of an acetylcholine receptorlike antigen on the surface of chick ciliary ganglion neurons in cell culture. J. Neurosci. 6: 946-953.

Sotelo, C. (1968) Permanence of postsynaptic specializations in the frog sympathetic ganglion cells after denervation. Exp. Brain Res. 6: 294-305.

Stollberg, J., and D. K. Berg (1987) Neuronal acetylcholine receptors: Fate of surface and internal pools in cell culture. J. Neurosci. 7: 18091815 .

Stollberg, J., P. J. Whiting, J. M. Lindstrom, and D. K. Berg (1986) Functional blockade of neuronal acetylcholine receptors by antisera to a putative receptor from brain. Brain Res. 378: 179-182.

Tzartos, S. J., D. E. Rand, B. L. Einarson, and J. M. Lindstrom (1981) Mapping of surface structures of Electrophorus acetylcholine receptor using monoclonal antibodies. J. Biol. Chem. 256: 8635-8645.

Westrum, L. E. (1969) Electron microscopy of degeneration in the lateral olfactory tract and plexiform layer of the prepyriform cortex of the rat. Z. Zellforsch. 98: 157-187.

Willingham, M. C. (1980) Electron microscopic immunocytochemical localization of intracellular antigens in cultured cells: The EGS and ferritin bridge procedures. Histochem. J. 12: 419-434. 